\title{
Study of Effect of Variation of lonic Strength of the Medium on Velocity Constant of Ru(III) Catalyzed Oxidation of Hydroxy Benzoic Acids by Chloramine-T in Acidic Medium
}

\author{
PARMOD KUMAR \\ CCS University, Meerut, India. \\ ${ }^{*}$ Corresponding author E-mail: parmodkaushik1108@gmail.com \\ http://dx.doi.org/10.13005/ojc/290427
}

(Received: September 18, 2013; Accepted: October 10, 2013)

\begin{abstract}
In the present study the effect of variation of ionic strength of the medium on rate of oxidation of hydroxy benzoic acids as its effect provides some clues regarding the nature of reactive species involved in the rate determining step. In order to realize the above aim the experiments has been carried out which ultimately concluded that ionic strength variation does not change the reaction velocity constant significantly.
\end{abstract}

Key words: Ortho-hydroxy bezoic acid (0-HBA), meta-hydroxy bezoic acid (m-HBA), para-hydroxy bezoic acid ( $p-H B A)$, Ruthenium chloride $(R u(I I I))$, Chloramine-T (CAT), perchloric acid $\left(\mathrm{HClO}_{4}\right)$, Pottassium chloride $(\mathrm{Kcl})$, sodium perchlorate $\left(\mathrm{NaClO}_{4}\right)$.

\section{INTRODUCTION}

\section{lonic strength}

The rate of reaction between charged species are affected strongly by the ionic strength of the solution, which is defined as: $-I=1 / 2 \sum c_{i} Z_{i}^{2}$

where $c_{i}$ is the concentration of each ion present in the solution and $Z_{i}$ is its charge number. When the reacting species are of the same sign, an increase in ionic strength increases the rate, when ions of opposite signs react, there is a decrease in rate with increasing ionic strength. Bronsted, Bjerrum, Christiansen, Davis and Scatchard suggested that the rate of reaction between species $A$ and $B$ should be expressed as -

$$
v=k_{0}[A][B] \gamma_{A}, \gamma_{B}, \gamma_{x} \text { and } \gamma_{i}
$$

where $\mathrm{k}_{0}$ is a constant at a given temperature, $g_{A}$ and $g_{B}$ are the activity coefficient of the reactant and $g_{x}$ is collision complex. According to DebyeHuckel theory, the activity coefficient $g_{i}$ of an ion is related to the ionic strength by the equation -

$$
\log \gamma_{i}=-\left.B Z_{i}^{2}\right|^{1 / 2}
$$

where $z_{i}$ is the charge number of the ion and $B$ is a quantity, whose value can be calculated from Debye-Huckel equation. From equation (1) the rate constant $k(=v / /[A][B])$ is - 


$$
k=\mathrm{k}_{0} \frac{\gamma A \gamma B}{\gamma x}
$$

$$
\log \frac{k}{k_{0}}=1.02 \mathrm{Z}_{\mathrm{A}} \mathrm{Z}_{\mathrm{B}}\left(\mathrm{I} / \mathrm{mol} . \mathrm{dm}^{-3}\right)^{1 / 2}
$$

(2) becomes-

which is logarithmic form including equation

$$
\log k=\log k_{0}+\left.2 B Z_{A} Z_{B}\right|^{1 / 2}
$$

For an aqueous solution at $25^{\circ} \mathrm{C}$ this equation becomes -
According to equation (5) a plot of log $\mathrm{k}$ versus $\left(\mathrm{l} / \mathrm{mol} \text {. } \mathrm{dm}^{-3}\right)^{1 / 2}$ will give a straight line of slope $1.02 Z_{A} Z_{B}$ and intercept is log $k_{0}$. If one of the reactants is a neutral molecule, $Z_{A} Z_{B}$ is zero and the rate constant is expected to be independent of the ionic strength. The rate constant of a reaction

\begin{tabular}{|c|c|c|c|}
\hline \multicolumn{4}{|c|}{ Temperature $-35^{\circ} \mathrm{C}$} \\
\hline $\begin{array}{l}{\left[\mathrm{NaClO}_{4}\right] \times 10^{3}} \\
\mathrm{~mol} \mathrm{dm}^{-3}\end{array}$ & $\begin{array}{c}\text { lonic strength } \\
\left(\mu \times 10^{3}\right) \mathrm{mol} \mathrm{dm}^{-3}\end{array}$ & $\begin{array}{l}(-\mathrm{dc} / \mathrm{dt}) \times 10^{8} \\
\mathrm{~mol} \mathrm{dm} \mathrm{m}^{-3} \mathrm{~s}^{-1}\end{array}$ & $\begin{array}{c}k_{1} \times 10^{4} \\
\mathbf{s}^{-1}\end{array}$ \\
\hline 0.00 & 2.00 & 1.56 & 2.00 \\
\hline 1.00 & 3.00 & 1.77 & 2.27 \\
\hline 1.50 & 3.50 & 1.73 & 2.22 \\
\hline 2.00 & 4.00 & 1.53 & 1.96 \\
\hline 2.50 & 4.50 & 1.51 & 1.94 \\
\hline 3.00 & 5.00 & 1.59 & 2.06 \\
\hline 3.50 & 5.50 & 1.66 & 2.13 \\
\hline
\end{tabular}
between an ion and a neutral molecule should vary

Table 1 (a):

$[\mathrm{CAT}]^{\star}=7.80 \times 10^{-5} \mathrm{~mol} \mathrm{dm}{ }^{-3}$ at which $(-\mathrm{dc} / \mathrm{dt})$ has been calculated

Table 1 (b):

$[\mathrm{m}-\mathrm{HBA}]=1.00 \times 10^{-3} \mathrm{~mol} \mathrm{dm}^{-3}$

$[C A T]=1.00 \times 10^{-4} \mathrm{~mol} \mathrm{dm}^{-3}$

$[\mathrm{KCl}]=1.00 \times 10^{-3} \mathrm{~mol} \mathrm{dm}^{-3}$

\begin{tabular}{|c|c|c|c|}
\hline \multicolumn{4}{|c|}{ Temperature $-35^{\circ} \mathrm{C}$} \\
\hline $\begin{array}{l}{\left[\mathrm{NaClO}_{4}\right] \times 10^{3}} \\
\mathrm{~mol} \mathrm{dm}^{-3}\end{array}$ & $\begin{array}{c}\text { lonic strength } \\
\left(\mu \times 10^{3}\right) \mathrm{mol} \mathrm{dm}^{-3}\end{array}$ & $\begin{array}{l}(-\mathrm{dc} / \mathrm{dt}) \times 10^{8} \\
\mathrm{~mol} \mathrm{dm^{-3 }} \mathrm{s}^{-1}\end{array}$ & $\begin{array}{c}k_{1} \times 10^{4} \\
s^{-1}\end{array}$ \\
\hline 0.00 & 6.00 & 0.89 & 1.00 \\
\hline 0.50 & 6.50 & 0.92 & 1.03 \\
\hline 1.50 & 7.50 & 0.90 & 1.01 \\
\hline 2.50 & 8.50 & 0.93 & 1.04 \\
\hline 3.50 & 9.50 & 0.96 & 1.07 \\
\hline 4.50 & 10.50 & 0.94 & 1.05 \\
\hline 5.50 & 11.50 & 0.97 & 1.08 \\
\hline
\end{tabular}

$\left[\mathrm{HClO}_{4}\right]=6.00 \times 10^{-3} \mathrm{~mol} \mathrm{dm}^{-3}$

$[\mathrm{Ru}(\mathrm{III})]=1.00 \times 10^{-6} \mathrm{~mol} \mathrm{dm}^{-3}$

$[\mathrm{CAT}]^{*}=8.90 \times 10^{-5} \mathrm{~mol} \mathrm{dm}^{-3}$ at which $(-\mathrm{dc} / \mathrm{dt})$ has been calculated. 
with the first power of the ionic strength instead of with the square root. $\mathrm{k}=\mathrm{k}_{0}(1+\mathrm{bl})$ so the rate constant should vary linearly with $\mathrm{I}$.

Chloramine- $\mathrm{T}$ is the sodium derivative of $\mathrm{N}$-chloro p-toluene sulphonamide $\mathrm{CH}_{3} \mathrm{C}_{6} \mathrm{H}_{4} \mathrm{SO}_{2} \mathrm{NCl}$ Na. $3 \mathrm{H}_{2} \mathrm{O}$ (molecular weight 281.70), prepared easily and mainly from p-toluene sulphonic acid, a cheap by product in the manufacture of saccharin. It is a less familiar but very potent oxidizing agent in alkaline as well as in acid media. A survey of existing literature showed that chloramine-T has been used for the determination of numerous inorganic and organic substances. It has been reported that in acidic medium (Hydrochloric acid), $\left[\mathrm{RuCl}_{6}\right]^{-3}$ is taken as reactive species. For the sake of simplicity, $\left[\mathrm{RuCl}_{6}\right]^{-3}$ is written as $[R u(I I I)]$ in the same scheme. $R u(I I I)$ chloride exists as $\left[\mathrm{Ru}\left(\mathrm{H}_{2} \mathrm{O}\right)_{6}\right]^{3+}$ in dil. $\mathrm{HCl}$. Such type of aqueous complexes are known to exist in the form $\left[\mathrm{Ru}\left(\mathrm{H}_{2} \mathrm{O}\right)_{5} \mathrm{OH}\right]^{2+}$ in equilibrium with hexa aquo form.

$$
\left[\mathrm{Ru}\left(\mathrm{H}_{2} \mathrm{O}\right)_{6}\right]^{3+} \rightleftharpoons\left[\mathrm{Ru}\left(\mathrm{H}_{2} \mathrm{O}\right)_{5} \mathrm{OH}\right]^{2+}+\mathrm{H}^{+}
$$

$\left[\mathrm{RuCl}_{6}\right]^{-3}$ which is in equilibrium with $\left[\mathrm{Ru}\left(\mathrm{H}_{2} \mathrm{O}\right)_{5} \mathrm{OH}\right]^{-2}$ in the following manner.

$$
\left[\mathrm{RuCl}_{6}\right]^{-3}+\mathrm{H} 2 \mathrm{O} \rightleftharpoons\left[\mathrm{RuCl}_{5} \cdot \mathrm{H}_{2} \mathrm{O}\right]^{2-}+\mathrm{Cl}^{-}
$$

Table 1(c):

$$
\begin{aligned}
& {[p-H B A]=2.00 \times 10^{-3} \mathrm{~mol} \mathrm{dm}^{-3}} \\
& {[\mathrm{CAT}]=1.00 \times 10^{-4} \mathrm{~mol} \mathrm{dm}^{-3}} \\
& {[\mathrm{KCl}]=1.00 \times 10^{-3} \mathrm{~mol} \mathrm{dm}^{-3}}
\end{aligned}
$$

\begin{tabular}{|c|c|c|c|}
\hline \multicolumn{4}{|c|}{ Temperature $-35^{\circ} \mathrm{C}$} \\
\hline $\begin{array}{l}{\left[\mathrm{NaClO}_{4}\right] \times 10^{3}} \\
\mathrm{~mol} \mathrm{dm}^{-3}\end{array}$ & $\begin{array}{l}\text { lonic strength } \\
\left(\mu \times 10^{3}\right) \mathrm{mol} \mathrm{dm}^{-3}\end{array}$ & $\begin{array}{l}(-\mathrm{dc} / \mathrm{dt}) \times 10^{8} \\
\mathrm{~mol} \mathrm{dm^{-3 }} \mathrm{s}^{-1}\end{array}$ & $\begin{array}{c}k_{1} \times 10^{4} \\
s^{-1}\end{array}$ \\
\hline 0.00 & 4.00 & 2.63 & 3.46 \\
\hline 1.00 & 5.00 & 2.60 & 3.42 \\
\hline 2.00 & 6.00 & 2.53 & 3.32 \\
\hline 3.00 & 7.00 & 2.56 & 3.36 \\
\hline 4.00 & 8.00 & 2.65 & 3.48 \\
\hline 5.00 & 9.00 & 2.75 & 3.61 \\
\hline 6.00 & 10.00 & 2.55 & 3.35 \\
\hline
\end{tabular}

$$
\begin{aligned}
& {\left[\mathrm{HClO}_{4}\right]=2.00 \times 10^{-3} \mathrm{~mol} \mathrm{dm}^{-3}} \\
& {[\mathrm{Ru}(\mathrm{III})]=1.00 \times 10^{-6} \mathrm{~mol} \mathrm{dm}^{-3}}
\end{aligned}
$$

$[\mathrm{CAT}]^{*}=7.60 \times 10^{-5} \mathrm{~mol} \mathrm{dm}^{-3}$ at which (-dc/dt) has been calculated.

This equilibrium in right direction would be highly favoured in acidic medium, suggesting that $\left[\mathrm{RuCl}_{5} \cdot \mathrm{H}_{2} \mathrm{O}\right]^{2-}$ in the actual reactive species of Ruthenium (III) chloride in present work.

\section{EXPERIMENTAL}

To determine the effect of variation of Ionic strength of velocity content of $\mathrm{Ru}(\mathrm{III})$ Catalysed oxidation of hydroxyl benzoic acid the various experiments with varying ionic strength (affected by addition of suitable amount of sodium perchlorate) at constant concentration of other reactants have been carried out in oxidation of each hydroxyl benzoic acid and the result have been reported in table $A, B$ and $C$ respectively in ortho- hydroxy benzoic acid, meta- hydroxy benzoic acid, para-hydroxy benzoic acid in a summarized way.

\section{CONCLUSION}

It is clear from the result of the tables A, B \& $C$ that upon increasing the concentration of sodium perchlorate, the ionic strength variation does not change the reaction velocity constants significantly. Thus there is negligence effect of ionic strength of the medium on reaction. 


\section{REFERENCES}

1. F. Pearson, Kinetics and Mechanism, $2^{\text {nd }}$ Edn.

2. J.N. Bronsted, Z. Phys. Chem., 102: 169 (1922).

3. J.N. Brosted, J. Am. Chem. Soc., 49: 435 (1937).

4. N. Bjerrum, Z. Physik. Chem., 108: 82 (1924): 118: 251 (1925).

5. J.A. Christiansen, Z. Phys. Chem., 108: 82 (1924).

6. F.A. Cotton and G. Wilkinson, "Adanced Inorganic Chemistry", Wiley, New York, $2^{\text {nd }}$ Edn., p. 152 (1966).

7. R.E. Connick and D.A. Fins, J. Am. Chem. Soc., 83, 3474 (1961), 82: 4187 (1960)..

8. H.H. Cady and R.E. Connick, J. Am. Chem. Soc., 80: 2646 (1958).

9. J.R. Backhours, F.D. Doyer and N. Shales,
Proc. Roy Soc., 83: 146 (1950).

10. J.C. Morris, J.A. Salazar and M.A. Winemann, J. Am. Chem. Soc., 70: 2036 (1948).

11. H. Alvi, M. Taheri and M. Daryani, Orient J. Chem., 29(1): 135-143 (2013).

12. F.E. Hardy and J.P. Johnston, J. Chem. Soc., Perkin-II, 642 (1973).

13. Y.K. Gupta and K.S. Gupta, J. Chem. Educ., 61: 972 (1984).

14. H.S. Yathirajan, D.S. Mahadevappa and Rangaswamy, Talanta, 27: 52-54 (1980).

15. A.I. Vogal, In quantitative organic analysis (Part 3) (ELBS, Longman, London), 739 (1958).

16. G.C. Amin, S.D. Wadekar and H.U. Mehta, Ind. J. Tex. Res., 2, 20 (1997).

17. A. Kumar, Z. Gani and S. Bashir, Orient J. Chem., 29(2): 441-450 (2013). 